\title{
EDUCAÇÃO E CIDADE: PUBLICAÇÕES DIRECIONADAS À JUVENTUDE
}

\author{
GUSTAVO HENRIQUE WOLLMANN ${ }^{1}$ \\ ORCID: https://orcid.org/0000-0003-3866-8383 \\ NEIVA DE ASSIS ${ }^{2}$ \\ ORCID: https://orcid.org/0000-0002-5530-2095
}

\begin{abstract}
RESUMO: Nesta pesquisa bibliográfica, objetivou-se analisar publicações científicas com a temática educação e cidade, focalizando oportunidades educadoras proporcionadas a jovens na cidade. Através de busca no EBSCO Discovery Service, com os descritores "cidade", "educação" e "juventude", selecionaram-se 112 artigos, analisados em nove categorias: 1) Área do Conhecimento; 2) Público-alvo; 3) Área Geográfica; 4) Tipo de Pesquisa; 5) Instrumento Metodológico; 6) Base Teórica; 7) Atividade Desenvolvida; 8) Principais Resultados; e 9) Discussão sobre Cidade. Os resultados revelam diversos usos do território no exercício educativo - variando entre áreas urbanas e rurais, centrais e periféricas -, destacando possibilidades de educar a/com a juventude em práticas urbanas, locais e não institucionalizadas. A escola ainda aparece como central para encontros educativos e criações das juventudes, sendo necessário atividades mais próximas do território. Constatamos significativas experiências educativas territorializadas baseadas na Educação Popular, de Paulo Freire, valorizando os saberes locais, a prática social e relacionando cultura e educação não formal. Concluímos sustentando que as cidades são como arenas interdisciplinares potentes para práticas educativas territorialmente estruturadas, articuladas com vivências e características locais.
\end{abstract}

Palavras-chave: Educação, cidades, juventudes.

\section{EDUCATION AND THE CITY: PUBLICATIONS DIRECTED TO YOUTH}

\begin{abstract}
This bibliographic research aimed to analyze scientific publications with the theme education and the city, focusing on educational opportunities provided to young people in the city. Through a search in a EBSCO Discovery Service, using the descriptors "city", "education", and "youth", 112 articles were selected and analyzed in nine categories: 1) Knowledge Area; 2) Target Audience; 3) Geographic Area; 4) Type of Research; 5) Methodological tools; 6) Theoretical basis; 7) Activity Developed; 8) Main Results; and 9) Discussion about the city. The results reveal several uses of the territory in education - ranging between urban and rural, central and outskirt areas - highlighting

\footnotetext{
${ }^{1}$ Graduando em Psicologia pela Universidade Federal de Santa Catarina (UFSC). Pesquisador do Programa Institucional de Bolsas de Iniciação Científica (PIBIC/CNPq — BIP/UFSC) durante o ciclo 2018/2019. Florianópolis, SC, Brasil. <ghwollmann@gmail.com>

2 Professora do Departamento de Psicologia da Universidade Federal de Santa Catarina (UFSC), membro do Laboratório de Psicologia Escolar e Educacional (LAPEE/UFSC). Florianópolis, SC, Brasil.<neiva.assis@ufsc.br> 
possibilities of educating youth through urban, local, and non-institutionalized practices. School still seems central for educational meetings and youth creations, requiring activities closer to its territory. We found significant territorialized educational experiences based on Paulo Freire's Popular Education, valuing local knowledge, social practice, and relating culture and non-formal education. We conclude by affirming that cities are powerful interdisciplinary arenas for territorially structured educational practices, articulated with local experiences and characteristics.

Keywords: Education, cities, youth.

\section{EDUCACIÓN Y CIUDAD: PUBLICACIONES DIRIGIDAS A LA JUVENTUD}

RESUMEN: Esta investigación bibliográfica tuvo como objetivo analizar publicaciones científicas con el tema educación y la ciudad, centrándose en las oportunidades educativas proporcionadas a los jóvenes de la ciudad. A través de la búsqueda en el EBSCO Discovery Service, con los descriptores "ciudad", "educación" y "juventud", fueron seleccionados 112 artículos, analizados en nueve categorías: 1) Área de conocimiento; 2) Público objetivo; 3) área geográfica; 4) Tipo de investigación; 5) instrumento metodológico; 6) base teórica; 7) Actividad desarrollada; 8) Resultados principales; y 9) Discusión sobre Ciudad. Los resultados revelan varios usos del territorio en el ejercicio educativo, que van por las áreas urbanas y rurales, centrales y periféricas, destacando las posibilidades de educar a los jóvenes en prácticas urbanas, locales y no institucionalizadas. La escuela todavía aparece como central para reuniones educativas y creaciones juveniles, que requieren actividades más cercanas al territorio. Encontramos experiencias educativas territorializadas significativas basadas en la Educación Popular, de Paulo Freire, que valora el conocimiento local, la práctica social y relaciona la cultura y la educación no formal. Concluimos afirmando que las ciudades son espacios interdisciplinarios poderosos para prácticas educativas estructuradas territorialmente, articuladas con vivencias y características locales.

Palabras clave: Educación, ciudades, juventudes.

\section{INTRODUÇÃO}

Em imagens, diferentes cidades apresentam elementos semelhantes entre si: casas, ruas, prédios e parques são algumas das figuras que podem constituir imaginários comuns sobre o ambiente urbano. À distância ou imóvel, assim, a paisagem da cidade constitui-se de estruturas inanimadas, objetos, componentes que, por vezes, ultrapassam a escala humana (SANTOS, 2006; GEHL, 2015).

Acima de um retrato, contudo, uma cidade caracteriza-se também pelos movimentos que nela se desenrolam e pelos papéis assumidos por suas estruturas para permitirem que essa dinâmica viva ocorra (SANTOS, 2006). Funcionalmente ocupadas, áreas urbanas edificadas sustentam comércios, indústrias, moradias e atividades para as pessoas que nelas vivem, imprimindo suas marcas (NOGUEIRA, 2009).

O movimento das ruas, com seus encontros e conflitos, e as diferentes instituições presentes na urbe, como as escolas, são exemplos de elementos da cidade característicos de sua ocupação promovida por sujeitos. Elo entre funcionalidade e estrutura, a atividade humana permite superar o arquitetado, instituindo o espaço como ente geográfico próprio ao estudo das cidades (SANTOS, 2006).

Experimentada por variados grupos humanos, em contato nas ruas e atravessados por suas próprias características sociais - como classe, gênero, etnia e idade -, as cidades organizam processos de subjetivação resultantes e auxiliares da prática da alteridade (CASTRO, 2001; NOGUEIRA, 2009). Ao serem incorporadas subjetivamente, essas vivências possíveis na cidade retroalimentam práticas e leituras urbanas, possibilitando aos sujeitos produzirem sentidos, localizarem-se na trama da cidade e sobre ela agirem. 
Mesmo os jovens, contemporaneamente privados dessa experiência urbana - afastados das ruas por conta de perigos urbanos e com a decorrente institucionalização das práticas educativas em territórios limitados pelo ambiente escolar (CASTRO, 2001; COIMBRA; NASCIMENTO, 2003) -, encontram brechas através das quais estabelecem contatos potentes com a cidade, como em atividades extraclasse ou mesmo em seus caminhos de casa à escola (ASSIS; ZANELLA, 2016). As juventudes engendram outros ritmos para além dos muros domiciliares e escolares, dialogando com a espacialidade urbana em redes de sociabilidade e tendo encontros atravessados por conflitos, brincadeiras e afetos (CASTRO, 2001; PEREIRA, 2016).

Apostando na cidade como arena educativa para as juventudes, promotora de processos subjetivos inclusivos e de vivências éticas, estéticas e solidárias (COIMBRA; NASCIMENTO, 2003), este estudo teve como objetivo investigar as publicações científicas sobre a temática educação e cidade, analisando as oportunidades educadoras proporcionadas a jovens através do território. Focalizamos as particularidades das comunidades e das juventudes, enfatizando a relevância destas na vida comunitária (GONÇALVES, 2006).

Em síntese, interessou-nos conhecer as publicações científicas que abordam a relação entre cidade e educação, caracterizando as experiências educativas encontradas na tentativa de fortalecer a interface entre as áreas da Psicologia e da Educação. Por meio de levantamento bibliográfico, 112 artigos foram analisados, categorizados e discutidos.

\section{MÉTODO}

Este trabalho tem caráter investigativo, bibliográfico, descritivo e inventariante (FERREIRA, 2002) e destina-se a um levantamento da produção científica disponível sobre o tema discutido na plataforma EBSCO Discovery Service (EDS) - ferramenta oferecida pelo portal de periódicos da Coordenação de Aperfeiçoamento de Pessoal de Nível Superior (CAPES), que agrupa a totalidade de periódicos da Universidade Federal de Santa Catarina (UFSC), permitindo buscas unificadas.

$\mathrm{Na}$ primeira etapa de buscas pela literatura analisada, ocorrida em setembro de 2018, buscou-se por textos disponíveis integralmente, revisados por pares e sem recorte de data ou idioma, usando-se três descritores conectados entre si pelo operador booleano "and": "cidade", "educação" e "juventude". Tais descritores, utilizados em língua portuguesa, estreitaram os resultados sobretudo às publicações de países com essa língua, como Brasil, Portugal, Cabo Verde e Angola, contando também com textos em outras línguas, mas com resumos em português.

A escolha por três descritores amplos, mesmo resultando num grande número de artigos distantes da proposta de estudo e que precisaram ser excluídos - como os que usavam "cidade" apenas para localizar um município, sem se aproximar de "cidade" como tema -, mostrou-se acertada por trazer também um maior número de artigos pertinentes ao estudo. Foram encontrados 2077 resultados, restando 1828 após a exclusão automática de 249 textos duplicados. Todos foram inicialmente examinados a partir de seus títulos - normalmente informativos dos principais elementos e conteúdo dos trabalhos (FERREIRA, 2002) -, momento em que novos artigos foram descartados: por serem textos duplicados não identificados anteriormente pela ferramenta de buscas, ou por não se enquadrarem nos critérios de seleção definidos para o estudo.

Os critérios guiam-se através dos três eixos temáticos fundamentais ao trabalho - cidade, educação e juventude -, sendo selecionados os artigos que apresentaram todos os três temas, tanto em sentidos consonantes com nossos interesses como através de discussões secundárias, desde que antevendo, ao menos, caminhos para diálogos temáticos. Determinado texto, assim, não necessariamente precisou tratar da cidade como dispositivo para práticas educativas, mas abordar todos os temas acima citados, ainda que promovendo outras discussões. A ausência de diálogo com um ou mais temas resultou na exclusão dos trabalhos.

Apenas 152 dos 1828 trabalhos iniciais foram selecionados para a fase seguinte de análise, desta vez através da leitura de seus resumos - ora importantes por facilitarem o acesso a dados gerais 
sobre os trabalhos, ora limitados por conteúdos informativos não uniformes e pouco informativos, levando à leitura integral dos textos.

Concluída a leitura dos resumos, e a partir dos critérios citados, 40 novos trabalhos foram excluídos, restando efetivamente 112 artigos a serem analisados, categorizados e discutidos. Estes foram listados alfabeticamente segundo seus títulos e organizados com outros dados básicos: autor, instituição, palavras-chave, ano e revista. Em novas leituras, tanto dos resumos como dos textos na íntegra, todos os artigos foram classificados através de nove categorias de análise de dados, inspiradas nas propostas metodológicas de Zanella e Titon (2005) e de Assis, Zanella e Rosa (2014): 1) Área do Conhecimento; 2) Público-alvo; 3) Área Geográfica; 4) Tipo de Pesquisa; 5) Instrumento Metodológico; 6) Base Teórica; 7) Atividade Desenvolvida; 8) Principais Resultados; e 9) Discussão sobre Cidade.

A categoria Área do Conhecimento contou com dez subcategorias, elencadas a partir da formação e dos vínculos acadêmicos dos autores de cada estudo. Usou-se como referência a Tabela de Áreas do Conhecimento/Avaliação do portal CAPES (2017). As áreas identificadas foram: a) "Antropologia"; b) "Ciências Sociais"; c) "Educação"; d) "Educação Física"; e) "Geografia"; f) "Psicologia"; g) "Sociologia"; e h) "Terapia Ocupacional". As pesquisas desenvolvidas em mais de uma área do conhecimento foram reunidas na subcategoria i) "Estudos Interdisciplinares", e as áreas com resultados menos expressivos foram agrupadas em j) "Outra Área".

Em Público-alvo, descrevem-se os períodos de vida dos participantes dos estudos, não atentando para faixas etárias numericamente delimitadas, visto que a maioria dos artigos não as anunciou. As subcategorias são: a) "Jovens"; b) "Crianças"; c) "Diversos Públicos", para estudos com grupos heterogêneos de participantes não definidos por períodos de vida; e d) "Não Identificado", nos estudos em que não localizamos dados sobre seus participantes.

A Área Geográfica informa também sobre os participantes dos estudos e foi estruturada em quatro subcategorias: a) "Urbano"; b) "Rural"; c) "Outra Área", para localidades diferentes das subcategorias anteriores; e d) "Indeterminada", para estudos em que não localizamos recortes regionais.

Para Tipo de Pesquisa, analisaram-se, em proximidade com os estudos de Gil (2008), os instrumentos técnicos empregados no desenvolvimento dos artigos, criando-se oito subcategorias: a) "Estudo de Campo", caracterizada pelo estudo presencial da estrutura de um grupo ou comunidade, tendendo a utilizar técnicas de observação; b) "Etnografia", com imersão mais próxima e profunda do pesquisador com seu campo de estudo; c) "Estudo de Caso", "aprofundado e exaustivo de um ou poucos objetos, de maneira que permita seu amplo e detalhado conhecimento" (GIL, 2008, p.57), com resultados em condição de hipóteses para situações complexas em que não é possível o emprego de levantamentos e experimentos; d) "Pesquisa Bibliográfica", desenvolvidas a partir de materiais já elaborados, como livros e artigos científicos; e) "Pesquisa Documental", utilizando materiais advindos de fontes diversas, como documentos em primeira mão - arquivos de instituições, cartas, fotografias e gravações - e segunda mão - relatórios de empresas e tabelas estatísticas; e f) "Pesquisa Participante", unificando Pesquisa-Ação, Pesquisa-Intervenção e Pesquisa-Participante, aproximadas pelo elemento comum da cooperação entre pesquisadores e sujeitos para a resolução de problemas coletivos - mesmo com certos autores, como Gil (2008), atribuindo características diferentes às três, o baixo número de estudos que as utilizaram levaram à sua união neste trabalho.

As duas últimas subcategorias referentes ao Tipo de Pesquisa foram: g) "Diversos Tipos de Pesquisa", para estudos com mais de um modelo de pesquisa; e h) "Outro", para reunir tipos de pesquisa numericamente menos expressivos. Como pondera Gil (2008, p. 50) a respeito desses modelos de pesquisa, a categoria Tipo de Pesquisa "não pode ser tomada como absolutamente rígida, visto que algumas pesquisas, em função de suas características, não se enquadram facilmente num ou noutro modelo".

Em Instrumento Metodológico foram identificadas as subcategorias: a) "Análise Documental"; b) "Outros Procedimentos de Campo"; c) "Entrevistas"; d) "Observação Participante"; e) "Revisão Bibliográfica"; e f) "Pesquisas Multimetodológicas". Há também as subcategorias g) "Outros Instrumentos", para estudos com procedimentos pouco utilizados, e h) "Instrumentos Não Identificados", para trabalhos sem procedimentos localizados. 
Para Base Teórica, criaram-se 11 subcategorias, relacionadas a teorias e autores utilizados como referência nos estudos analisados: a) "Escola de Frankfurt e Outros Marxistas"; b) "Estudos Culturais"; c) "Michel Foucault, Gilles Deleuze e Félix Guattari"; d) "Paulo Freire"; e) "Pedagogia Histórico-Crítica"; f) "Pierre Bourdieu"; g) "Psicologia Histórico-Cultural e/ou Círculo de Bakhtin"; h) "Walter Benjamin"; i) "Diversos Autores"; j) "Outros Autores", reunindo as bases numericamente menos expressivas; e k) "Não Identificado", para textos sem autores e teorias localizados.

As Atividades Desenvolvidas, realizadas com os participantes dos estudos, foram organizadas em dez subcategorias: a) "Atividades Artístico-Culturais"; b) "Ação Comunitária", para atividades envolvendo o encontro de atores locais, normalmente de uma mesma área; c) "Cultura HipHop", relacionadas às diversas manifestações do movimento - rap, break dance, grafite, beat box, DJs e MCs; d) "Educação Regular", para práticas em instituições de ensino; e) "Educação Física, Esporte e Lazer", reunindo iniciativas dos três campos; f) "Projeto Social e Políticas Públicas", referente sobretudo a atividades educativas não formais; g) "Uso da Rua e do Urbano", para trabalhos analisando diferentes formas de participar da cidade; h) "Diversas Atividades", em pesquisas com mais de uma prática; i) "Outras Atividades", para atividades numericamente menos expressivas; e j) "Atividades Não Identificadas", para textos sem atividades localizadas.

Principais Resultados mapeou os achados e conclusões elaborados nos estudos analisados, resultando em dez subcategorias: a) "Experiência coletiva artística modifica a relação com o espaço"; b) "Importância da relação entre a proposta escolar e ações comunitárias"; c) "Análise de políticas públicas voltadas à juventude: insuficiências e fragilidades"; d) "Experiências com música na cidade mobilizadoras de processos singulares e coletivos"; e) "Possibilidades e dificuldades de sujeitos rurais em práticas educativas e comunitárias"; f) "Potência do movimento juvenil na reivindicação do direito à participação na política da cidade"; g) "Aprendizagem de conteúdos curriculares mais significativa quando relacionada à cidade"; h) "Espaços marginalizados e violentos influenciando as experiências juvenis"; i) "Outro", para resultados menos expressivos numericamente; e j) "Não Identificado", para artigos sem resultados localizados.

Discussão Sobre Cidade, última categoria, abordou a espacialidade das cidades em sete subcategorias: a) "Cidade como Plano de Fundo", em que a cidade representa somente o cenário sobre o qual os sujeitos estão inseridos e vivem; b) "Cidade como Evento", destacando acontecimentos, festas e culturas tradicionais celebradas em áreas urbanas; c) "Cidade como Dispositivo", quando recursos da estrutura da cidade auxiliam na experiência urbana dos citadinos; d) "Cidade e Experimentações Singulares", tomando a cidade através dos pertencimentos individuais de sujeitos espacialmente inscritos; e) "Cidade como Coletivo", relativa a pertencimentos grupais sobre territórios comuns; f) "Diversas Discussões de Cidade", para estudos com diferentes perspectivas de cidade; e g) "Não Identificada", quando, mesmo presente, a discussão sobre cidades não foi aprofundada.

\section{RESULTADOS E DISCUSSÃO}

Os resultados deste levantamento são quantitativamente observáveis através da distribuição dos textos nas categorias anteriormente apresentadas, demandando uma análise crítica dos dados reunidos e a imersão nos artigos para desenvolver discussões teórico-metodológicas relevantes sobre as práticas educativas verificadas.

Dos 112 artigos analisados, 95 foram de autores vinculados a instituições brasileiras, sendo Rio de Janeiro (18,6\%), São Paulo (17,5\%) e Rio Grande do Sul (13,4\%) os estados com mais trabalhos selecionados. No Brasil, o Sudeste $(49,5 \%)$ concentra a maior parte dos estudos, seguido das regiões Sul $(22,7 \%)$, Nordeste $(21,6 \%)$, Norte $(4,4 \%)$ e Centro-Oeste $(2,1 \%)$. Como apontam Zanella e Titon (2005) e Assis, Zanella e Rosa (2014), esses valores relacionam-se com os números de universidades e programas de pós-graduação estabelecidos em cada região, verificáveis através da Avaliação Quadrienal 2017 da CAPES. O recente desenvolvimento desses cursos e programas também elucida a concentração de trabalhos publicados nos anos mais recentes: 2016 (31,3\%) destacou-se como o ano com mais trabalhos publicados sobre a temática; e, juntos, os anos de 2018, 2017, 2016 e 2015 reuniram 73,3\% dos materiais analisados, sendo o mais antigo datado de 2002. 
Inicialmente, na Área do Conhecimento, constataram-se estudos pertencentes à Educação (26,8\%), Estudos Interdisciplinares (21,4\%) e trabalhos produzidos pela Geografia (8\%). Houve artigos vinculados à Sociologia (8,9\%), à Antropologia (4,5\%) e outros, ainda, às Ciências Sociais $(5,4 \%)$, área formada pelas duas subcategorias anteriores. A Terapia Ocupacional (6,3\%) produziu mais materiais que a Psicologia (3,6\%) e a Educação Física (3,6\%); e a subcategoria Outra Área $(11,7 \%)$ reuniu estudos de: Administração; Saúde Coletiva; História; Serviço Social; Turismo; Desenvolvimento Local; Ciências da Comunicação e Enfermagem.

Compreendemos como natural a relevância assumida pela Educação entre as áreas do conhecimento envolvidas com o tema. Além disso, sendo que a escola é local por excelência das práticas educativas, mesmo ao buscar atividades desenvolvidas fora dos muros escolares, acabamos reencontrando-a como via para esta discussão: em análises de atividades curriculares escolares e não escolares (LOPES, 2016; ORZECHOWSKI, 2017); no emprego de recursos didáticos não convencionais em sala de aula (MELLO; LASTORIA; SANTOS, 2015); em práticas pedagógicas sustentadas na educação popular (COSTA, 2017; FERREIRA, 2018); na influência da espacialidade urbana sobre as possibilidades escolares (LEBOURG; COUTRIM, 2018; SANTIBAÑEZ, 2018); e em atividades pedagógicas que saem dos limites escolares e acessam a cidade (CHAIGAR; BORBA, 2016; MENDES; PÉREZ, 2016).

Outra área responsável por favorecer discussões de cidade no ambiente escolar é a Geografia, ao incorporar recursos didáticos diferenciados - de campo, cartográficos, tecnológicos e culturais - em seu domínio como componente curricular. Tais recursos valorizam as vivências cotidianas dos estudantes, aumentam o envolvimento destes com as aulas e promovem aprendizagens significativas, articuladas com a experiência cidadã (SILVA; RAINHA, 2013; PENHA; MELO, 2016; ALENCAR; SILVA, 2018).

Essa proximidade entre Educação e Geografia indica a qualidade interdisciplinar do tema estudado, característica fundamental às discussões propostas e presente na maioria dos trabalhos analisados. Além das áreas anteriormente listadas, a subcategoria Estudos Interdisciplinares conta também com: Artes Visuais; Arquitetura; Música; e Museologia.

Embora entendamos a Psicologia como relevante para a discussão dos temas deste estudo, houve poucos trabalhos associados à área. A Terapia Ocupacional, nesse sentido, adianta-se à Psicologia, analisando práticas e técnicas de terapeutas ocupacionais em atividades culturais locais e informais para o acompanhamento com jovens socialmente vulneráveis (LOPES et al., 2014; ALVES; OLIVEIRA; CHAVES, 2016; GONÇALVES, 2016). Os estudos em Psicologia dedicaram-se sobretudo a casos de violência e vulnerabilidade social não relacionados ao caráter educativo das cidades (ARPINI; QUINTANA; GONÇALVES, 2010; FAUSTINO; HÜNING, 2015; TAKEITI; VICENTIN, 2015); no entanto, Schwede e Zanella (2013) sinalizam para a possibilidade dessa discussão, destacando na polifonia das cidades um caminho para experiências diversificadas, produtoras de subjetividades.

Em Público-alvo, os Jovens (59,8\%) foram os mais presentes como participantes dos estudos, enquanto as Crianças $(4,5 \%)$ foram o público exclusivo para poucos trabalhos - consequência dos descritores eleitos para a busca em base de dados. Casos com Diversos Públicos (30,4\%) representaram parcela expressiva dos textos analisados, e Não Identificado (5,4\%) reuniu os estudos sem recortes precisos de seus participantes. Sem buscar insistir em faixas etárias delimitadas, consideramos, todavia, relevante relatar as idades mais comuns entre os estudos com dados numéricos: dos 17 aos 18 anos; dos 15 aos 16; e dos 19 aos 22.

A análise da Área Geográfica indicou os meios Urbano (75,9\%) e Rural (9,8\%) como principais cenários focalizados nos trabalhos - sendo possível examinar o meio Urbano em áreas de Centro $(50 \%)$ e Periferia $(25,9 \%)$. Áreas com características singulares - de florestas, costeiras, quilombolas, agrupamentos campesinos e reservas indígenas - compõem a subcategoria Outra Área $(5,4 \%)$, e estudos em áreas não descritas territorialmente foram reunidos em Indeterminada $(8,9 \%)$.

Os trabalhos em áreas periféricas destacam como os jovens moradores desses locais são marcados pela ausência de oportunidades e têm acesso restrito a bens materiais e simbólicos (LEITE; MELO, 2017), sendo alvos de projetos sociais e políticas públicas de caráter compensatório. Os 
estudos (ABRANTES; TEIXEIRA, 2014; TOMMASI, 2014a; CECCHETTO; CORRÊA; FARIAS, 2016; PASQUIM; CAMPOS; SOARES, 2016) indicam que tais iniciativas individualizam e psicologizam problemas que são sociais, não implicando a transformação das estruturas escolares e comunitárias e limitando-se à tentativa de produzir ordem e afastar a juventude pobre, vista como perigosa, do crime.

Entre as numerosas atividades localizadas na periferia, no entanto, estão também práticas juvenis desinstitucionalizadas, normalmente relacionadas a culturas urbanas periféricas, como o Hip Hop. Em redes intersubjetivas, esses jovens marginalizados estabelecem e fortalecem suas identidades sociais, tendo em comum as dificuldades socioeconômicas, suas demandas não atendidas e outras vulnerabilidades cotidianas, através das quais promovem iniciativas autônomas e cidadãs em que refletem criticamente suas realidades, reivindicam direitos, denunciam desigualdades, superam estigmas e resistem, coletivamente, às experiências de violência vividas, inserindo-se na trama política e social (RAPOSO, 2012; ALVES; OLIVEIRA; CHAVES, 2016; GUIMARÃES; CARVALHO, 2016; TAKEITI; VICENTIN, 2016; LARANJEIRA; IRIART; LUEDY, 2018).

Trabalhos desenvolvidos com juventudes rurais retratam os obstáculos enfrentados por esses jovens no acesso à educação regular - sobretudo ao ensino médio. Sem incentivo para ficarem no campo, com o baixo retorno financeiro do trabalho rural e frente a adversidades, tais como desigualdades de gênero e falta de alternativas de lazer, os jovens do interior têm o meio urbano e a ascensão acadêmica como caminhos para a melhoria na qualidade de vida. Ao entrarem em escolas urbanas, contudo, defrontam-se com dificuldades que alteram seus modos de estar no mundo, como grandes deslocamentos diários, novas formas de sociabilidade, preconceito sofrido por suas identidades interioranas e práticas pedagógicas guiadas por referenciais urbanos que não valorizam saberes rurais (MENEZES, 2009; BATISTA; MAZON, 2015; SOUZA; SOUZA; ORRICO, 2015; ZAGO, 2016; FRANZOI; FRANÇA; OLIVEIRA，2017; ZANOTTO; ALVES; SOMMERHALDER, 2017; LEBOURG; COUTRIM, 2018).

Em Tipo de Pesquisa, o Estudo de Caso (23,2\%) foi o instrumento técnico mais utilizado por pesquisadores, seguido por Estudo de Campo (14,3\%), Etnografia (13,4\%), Pesquisa Documental $(11,6 \%)$, Pesquisa Bibliográfica $(10,7 \%)$ e Pesquisa Participante (8\%). Diversos Tipos de Pesquisa $(7,1 \%)$ reuniu estudos com mais de um procedimento, e Trabalhos com estruturas não descritas anteriormente formam a subcategoria Outro $(11,6 \%)$.

As Etnografias são importantes nos estudos com juventudes urbanas, inscritas dinamicamente no território das cidades e detentoras de práticas ordenadas por redes de sociabilidade. Ao participarem de processos educativos, os pesquisadores acessam outras perspectivas sobre o desempenho escolar juvenil, a importância da escola para esse público, as identidades sociais dos estudantes, suas práticas coletivas informais, potências e afetos (SILVA, 2014; COELHO, 2016; MARTINS, 2016). Na Pesquisa Participante, que também conta com procedimentos valorosos aos estudos urbanos, a neutralidade deixa de ser uma possibilidade, e conhecer resulta do fazer-criar através de práticas e discursos de participantes e pesquisadores contextualmente localizados, atentos ao sensível (SCHWEDE; ZANELLA, 2013; LOPES et al., 2014; TORRALBA, 2018).

Entre os Instrumentos Metodológicos, as Entrevistas (21,4\%) foram o instrumento mais utilizado, com ênfase nas entrevistas semi-estruturadas. Análise Documental (17,9\%) e Revisão Bibliográfica (12,5\%) também foram instrumentos relevantes, sendo a Revisão, mesmo indiretamente, passo complementar para a maioria dos estudos. Observação Participante $(5,4 \%)$ e Outros Procedimentos de Campo (4,5\%) encerram a lista de instrumentos mais adotados, estes últimos uma categoria abrangente, destacadamente empírica: em Procedimentos de Campo, os pesquisadores atuam no horizonte prático e cotidiano dos sujeitos pesquisados (MONZELI; FERREIRA; LOPES, 2015; ALMEIDA; RIBEIRO JUNIOR; SOUZA, 2016; TAKEITI; VICENTIN, 2016). Outros Instrumentos $(7,1 \%)$ reúne estudos com procedimentos em menor número; e Instrumento Não Identificado $(3,6 \%)$, os estudos sem procedimentos localizados.

Houve muitas Pesquisas Multimetodológicas (27,7\%), sendo também a Entrevista e a Análise Documental seus procedimentos constituintes mais comuns. O uso coincidente de diferentes métodos indica a diversidade de ferramentas necessárias para operar sobre as práticas educativas, e 
trabalhos classificados em outras subcategorias contam também com procedimentos secundários, de apoio. Entre as metodologias acessórias, destacam-se questionários, grupos focais e oficinas, as últimas indicando a importância de metodologias interativas para o envolvimento ativo de sujeitos em contextos educativos (SCHWEDE; ZANELLA, 2013; SILVA; RAINHA, 2013; LOPES et al., 2014; GONÇALVES, 2016).

$\mathrm{Na}$ Base Teórica, a Escola de Frankfurt e Outros Marxistas (6,3\%) e Pierre Bourdieu (6,3\%) empataram como as bases mais utilizadas, seguidas por Paulo Freire $(5,4 \%)$ e pela união entre Michel Foucault, Gilles Deleuze e Félix Guattari (5,4\%). Pedagogia Histórico-Crítica (4,5\%), Estudos Culturais (4,5\%), Psicologia Histórico-Cultural e/ou Círculo de Bakhtin (2,7\%) e Walter Benjamin $(2,7 \%)$ concluem a lista de autores e teorias. Em Diversos Autores $(22,3 \%)$ estão textos fundamentados em mais de um autor ou teoria; e, em Outros (11,6\%), estão as referências numericamente menos expressivas. A subcategoria Não Identificado $(28,6 \%)$ destacou-se sobretudo devido à falta de dados fornecidos nos trabalhos sobre suas bases teóricas.

Elaborada por Paulo Freire, as práticas em Educação Popular destacaram-se nos estudos por problematizarem como passivos, tradicionais e excludentes os métodos formais de ensino, ilustrados na chamada Educação Bancária. Entendemos a qualidade dialógica da práxis educativa freiriana como razão para seu constante emprego teórico nas atividades urbanas analisadas. As propostas desse educador brasileiro visam fortalecer a identidade cultural dos educandos na busca por transformar suas realidades, valorizando vivências dos estudantes e seus saberes produzidos cotidianamente (ALENCAR; MARTINS; SILVA, 2015; COSTA, 2017; MACHADO; SANTOS, 2017; TSOLAKIS, 2018).

A Psicologia Histórico-Cultural e o Círculo de Bakhtin também contribuem para uma perspectiva educativa dialógica, em que a aprendizagem é mediada pelo encontro com um outro - um professor, uma cidade - dotado de cultura, tempo histórico e atravessado por tramas sociais: permeado, portanto, de discursos. Conhecimento formado em exercícios éticos, estéticos e políticos, nos quais as possibilidades educativas acompanham a experiência cotidiana dos que apreendem (SCHWEDE; ZANELLA, 2013; MENDES; PÉREZ, 2016; PENHA; MELO, 2016).

Para as Atividades Desenvolvidas, foram centrais as Atividades Artístico-Culturais (17\%), atividades da Educação Regular (13,4\%) e atividades de Projeto Social e Políticas Públicas (9,8\%). Cultura Hip-Hop (8\%), Uso da Rua e do Urbano (8\%), Ação Comunitária (7,1\%) e Educação Física, Esporte e Lazer $(4,5 \%)$ também foram atividades desenvolvidas. Houve ainda trabalhos com Diversas Atividades (9,8\%); Outras Atividades (8\%), reunindo as menos frequentes; e Atividades Não Identificadas (14,3\%). Essas Atividades dividem-se entre as sediadas em contextos educativos formais $(21,4 \%)$ - no sistema de ensino regular; não-formais $(22,3 \%)$ - via associações ou organizações instituídas fora do sistema regular de ensino; informais $(25 \%)$ - por atividades cotidianas e iniciativas desinstitucionalizadas; e as simultaneamente em mais de um desses contextos (31,3\%) (ASSIS; ZANELLA; ROSA, 2014; COSTA, 2014).

As Atividades Artístico-Culturais constituem arenas diversificadas para dinâmicas educativas ativas, criadoras e promotoras de saúde, ora como técnicas singulares, ora como manifestações coletivas tradicionais, muitas vezes locais, descentralizadas e politizadas (DIBA; D'OLIVEIRA, 2015; BARBOSA; FERREIRA, 2017). Ao valorizarem saberes e expressões populares estimulam encontros democráticos que modificam redes identitárias, territoriais e de sociabilidade (LIBERATO, 2014; ARAÚJO; NEVES, 2017). Arte e cultura podem contribuir para a análise crítica de problemas sociais - embora possam também servir como instrumentos repositores de desigualdades (LIMA, 2002) -, assumindo caráter pedagógico, mediador de diversão e aprendizagem, e promovendo exercícios de cidadania criadores de novos sentidos sociais (SCHWEDE; ZANELLA, 2013; CASTRO; RIBEIRO, 2015; MELLO; LASTORIA; SANTOS, 2015; AFONSO, 2016; DAMASCENA, 2016; GROPPO; GOUSSAIN, 2016; LARANJEIRA; IRIART; LUEDY, 2018).

O Uso da Rua e do Urbano refere-se às numerosas formas com que sujeitos ocupam as cidades - a trabalho; atuando artística e culturalmente; transeuntes; moradores de rua. Os estudos indicam desde o acolhimento, sociabilidade e liberdade, à estigmatização, marginalização e impossibilidades enfrentadas por esses atores sociais (ARPINI; QUINTANA; GONÇALVES, 2010; 
MONZELI; FERREIRA; LOPES, 2015). O caráter educativo das ruas manifesta-se na discussão de ideias, na tensão entre atores, na união do cotidiano às estruturas circundantes, nas mazelas sociais e nos processos de resistência delas desencadeados, conduzindo os sujeitos a formularem valores e afetos entre si, incorporarem territórios, recriarem imaginários urbanos e dotarem de sentido e alteridade suas práticas sobre as cidades (RAMÍREZ, 2016; SIMÕES et al., 2017; OLIVEIRA; LACERDA, 2018; TORRALBA, 2018; TSOLAKIS, 2018).

A Cultura Hip-Hop, caracteristicamente periférica, fomenta redes identitárias críticas e socializantes, tornando socialmente ativas juventudes colocadas à margem - além de difundir músicas, gírias e modas, o movimento confronta problemas sociais através de práticas culturais e políticas, aumentando as possibilidades cidadãs dos jovens e conferindo novos sentidos à vida em comunidades pobres (MORENO; ALMEIDA, 2009; ALVES; OLIVEIRA; CHAVES, 2016; SANTOS; LEITE, 2017; SOUZA; BERNARDES, 2017). O Hip-Hop incide também sobre tramas territoriais e permite aos jovens expandirem circuitos urbanos e culturais, subvertendo estigmas em identidades positivas guiadas pelas qualidades educativas do movimento (MENEZES; COSTA; FERREIRA, 2010; RAPOSO, 2012; HINCAPIÉ, 2014; LÁZARO; SILVA, 2016).

Em Principais Resultados, a subcategoria "Experiência coletiva artística modifica a relação com o espaço" (20,5\%) concentrou o maior número de trabalhos. "Importância da relação entre a proposta escolar e ações comunitárias" (15,2\%) e "Análise de políticas públicas voltadas à juventude: insuficiências e fragilidades" (10,7\%) também foram resultados frequentes, seguidos por: "Experiências com música na cidade mobilizadora de processos singulares e coletivos" (8,9\%); "Possibilidades e dificuldades de sujeitos rurais em práticas educativas e comunitárias" (8,9\%); "Potência do movimento juvenil na reivindicação do direito à participação na política da cidade" (7,1\%); "Aprendizagem de conteúdos curriculares mais significativa quando relacionada à cidade" (6,3\%); "Espaços marginalizados e violentos influenciando as experiências juvenis" (6,3\%); e Outro (12,5\%). Em Não Identificado $(3,6 \%)$ estão os estudos sem resultados localizados.

A importância da cidade na aprendizagem de conteúdos curriculares esteve visível em propostas urbanas para a leitura cidadã de práticas sociais plurais - relacionadas à Educação Ambiental, Educação Física, História, Geografia e Literatura -, convidando a juventude a considerar seus entornos e histórias como elementos para o processo educativo, passíveis de serem coletivamente transformados (SOARES, 2015; MENDES; PÉREZ, 2016; ALENCAR; SILVA, 2018). Valorizados, saberes tradicionais e cotidianos articulam-se com saberes científicos e tecnológicos, permitindo analisar criticamente problemas sociais enfrentados por estudantes - muitas vezes com efeitos territoriais - e fortalecer identidades culturais locais (BENTO; THOMAZI, 2013; SILVA; RAINHA, 2013; LIBERATO, 2014; MELLO; LASTORIA; SANTOS, 2015).

O contato entre as escolas e suas localidades é uma via para deslocar práticas educativas para as cidades, envolvendo tanto a ida da escola a ambientes comunitários como o convite à comunidade para se envolver no dia a dia escolar (LEITE; CARVALHO, 2016; PENHA; MELO, 2016; SILVA, 2016). Embora a abertura ao bairro não constitua, sozinha, um processo crítico e transformador - como demonstra Dias (2014), em estudo sobre práticas escolares comunitárias durante a Era Vargas -, tal encontro pode, muitas vezes, resultar em iniciativas potentes: democráticas, fortalecedoras de identidades culturais e saberes locais, emancipatórias e dotadas de sentido, singular e coletivo, para jovens, moradores e docentes. (MENEZES; COSTA; FERREIRA, 2010; CHAIGAR; BORBA, 2016; LOPES, 2016; COSTA, 2017; FRANZOI; FRANÇA; OLIVEIRA, 2017; NUNES et al., 2017).

Territorialmente desarticuladas, ineficientes políticas públicas e projetos sociais destinados à juventude também se destacaram entre os Principais Resultados. Trata-se de iniciativas que instrumentalizam meios de controle sobre a juventude, assumem discursos hegemônicos e mercadológicos - como o empreendedorismo -, individualizam problemáticas sociais e desconsideram tramas sócio-históricas (TOMMASI, 2014a; FAUSTINO; HUNING, 2015; SILVA; GIOVINAZZO JUNIOR, 2016; PASQUIM; CAMPOS; SOARES, 2016). Tais iniciativas: têm caráter emergencial, não sendo reafirmadas como políticas de Estado (VIGANO; LAFFIN, 2017); fomentam alternativas de mobilidade social ilusórias, ou, em troca dela, limitam a autonomia dos sujeitos (TOMMASI, 2014b; 
CECCHETTO; CORRÊA; FARIAS, 2016); carregam controvérsias entre propostas e públicos-alvo (FAUSTINO; HUNING, 2015); promovem atividades desamparadas e fragmentadas (ANDRADE; BÓGUS, 2010; PASQUIM; CAMPOS; SOARES, 2016); estimulam valores competitivos e individualistas (PASQUIM; CAMPOS; SOARES, 2016); e esbarram na própria operacionalização (RIBEIRO; MACEDO, 2018). Para boas políticas públicas, os estudos recomendam atender às demandas juvenis e promover iniciativas transversais, coerentes com suas realidades sociais (ABRANTES; TEIXEIRA, 2014; FAUSTINO; HUNING, 2015; RIBEIRO; MACEDO, 2018).

$\mathrm{Na}$ categoria Discussão Sobre Cidade, a perspectiva mais adotada nos trabalhos foi a de Cidade como Plano de Fundo (31,3\%), seguida por Cidade e Experimentações Singulares (17\%), Cidade como Evento (16,1\%), Cidade como Dispositivo (10,7\%) e Cidade como Coletivo (10,7\%), com Diversas Discussões Sobre Cidade (3,6\%) e Não Identificada (10,7\%) concluindo a lista.

Em Cidade como Plano de Fundo, o tema das cidades é levantado somente para localizar contextos ambientais e sociais dos atores estudados. Os trabalhos que integram esta subcategoria discutem: vivências em comunidades periféricas, promovendo reconhecimento social crítico ou limitando-se a políticas públicas enviesadas (TOMMASI, 2014a; TOMMASI, 2014b; MOURA; OLIVEIRA; VASCONCELOS, 2015; ALVES; OLIVEIRA; CHAVES, 2016; CECCHETTO; CORREAA; FARIAS, 2016; PASQUIM; CAMPOS; SOARES, 2016); estigmatização e marginalização de jovens em situação de rua ou em cumprimento de medidas socioeducativas (ARPINI; QUINTANA; GONÇALVES, 2010; SANTOS; LEITE, 2017); dificuldades enfrentadas por moradores rurais e do semiárido (MENEZES, 2009; SALES, 2010; GENTILE; BURGOS, 2016; SIEBER; GOMES, 2016; ZAGO, 2016; SANTOS; BEZERRA NETO, 2017; ZANOTTO; ALVES; SOMMERHALDER, 2017; LEBOURG; COUTRIM, 2018); valorização da terra para grupos assentados (BATISTA; MAZON, 2015); e territórios virtuais estimulando novas e diversificadas redes de sociabilidade (SILVA; COUTO, 2012; GADEA et al., 2017).

A Cidade como Dispositivo focaliza diferentes estruturas urbanas acessíveis cotidianamente aos citadinos: teatros, museus e centros culturais, assegurando o direito às atividades artísticas e à fruição estética (GONÇALVES, 2016; MELO; AMARAL; CARVALHO, 2017); áreas verdes, auxiliando na educação ambiental (BENTO; THOMAZI, 2013); cinemas e clubes, promovendo lazer e diversão (SANTOS, 2008; AFONSO, 2016); patrimônios, convocando a leituras históricas, políticas e sociais (NASCIMENTO, 2013; MELO; AMARAL; CARVALHO, 2017); festas e comércios, estruturando cenas culturais (MOURA; GUERRA, 2016); e a rua, alicerce dessas todas estruturas e vivências, acolhendo aulas, performances, discussões, práticas artísticas, protestos e passeios (PENHA; MELO, 2016; ALVES; HALLAL, 2017; BARBOSA; FERREIRA, 2017; TSOLAKIS, 2018).

Cidade e Experimentações Singulares, caracterizada por pertencimentos particulares de atores espacialmente inscritos, evoca diversos elementos constituintes das atividades humanas sobre a cidade, dando indícios de como se constituem os sujeitos a partir do território: circuitos culturais e artísticos territorializados e socializantes, permitindo sujeitos se reinventarem nas tensões urbanas (KATAOKA; ORNAT, 2015; TAKEITI; VICENTIN, 2016; BARNART; BAUER, 2017; SOUZA; BERNARDES, 2017; CALAÇA; NASCIMENTO; DINIZ, 2018; LARANJEIRA; IRIART; LUEDY, 2018;); ativismo político juvenil contra desigualdades urbanas e educacionais (SANTIBAÑEZ, 2018); e identidades rurais metamorfoseadas no contato com a cidade (SOUZA; SOUZA; ORRICO, 2015). Os estigmas urbanos e sociais enfrentados por jovens marginalizados, por exemplo, podem produzir sofrimentos e dificuldades (SILVA, 2014; MONZELI; FERREIRA; LOPES, 2015); mas, com vivências de sociabilidade solidárias e o compartilhamento simbólico do cotidiano com seus pares, estes estigmas podem ser convertidos em estímulos com os quais os jovens se apropriam da cidade e subvertem os rótulos impostos, unindo o orgulho de seus lugares sociais à análise e atividade crítica contra estruturas sociais desiguais (RAPOSO, 2012; SILVA; RAINHA, 2013; HINCAPIÉ, 2014; LOPES et al., 2014; GUIMARÃES; CARVALHO, 2016; TAKEITI; VICENTIN, 2016).

Considerando as territorialidades com sentidos partilhados, produzidas no encontro entre sujeitos sobre territórios comuns, Cidade como Coletivo valoriza iniciativas que articulam atores e culturas locais (MENEZES; COSTA; FERREIRA, 2010; SILVA, 2016), em práticas sociais 
comunitárias e com elementos identitários e valores sociais compartilhados, mesmo em meio às híbridas e múltiplas identidades individuais resultantes de vivências singulares (MISSAU; RONSINI, 2012; CORREIA-LIMA; RIGO; SANTOS, 2016; MARTINS, 2016; MENDES; PÉREZ, 2016; NUNES et al., 2017).

\section{CONSIDERAÇÕES FINAIS}

Este estudo propôs-se a investigar práticas educativas presentes na cidade, buscando iniciativas formuladas por e/ou para a juventude e analisando a relevância de tais iniciativas em favor de processos subjetivos, singulares e coletivos.

Os resultados revelam diversos usos do território no exercício de atividades urbanas, por vezes anunciadas como educativas, por vezes cotidianas, informais, e ainda assim constituintes de movimentos de aprendizagem. Trabalhos em contextos periféricos e rurais diversificaram as narrativas juvenis sobre as cidades, indicando vivências urbanas particulares para jovens afastados das áreas urbanas centrais.

Esta revisão bibliográfica reuniu importantes materiais com as temáticas educação e cidade, trazendo abordagens teórico-metodológicas distintas, produzidos em diferentes locais e envolvendo áreas de conhecimento diversificadas - embora com baixo número de estudos da Psicologia. Constatamos significativas experiências educativas territorializadas baseadas na Educação Popular, de Paulo Freire, valorizando os saberes locais, a prática social e relacionando cultura e educação não formal (ALVES; OLIVEIRA; CHAVES, 2016). Concluímos sustentando que as cidades são como arenas interdisciplinares potentes para práticas educativas territorialmente estruturadas, articuladas com vivências e características locais.

Os trabalhos indicaram a importância de atividades artísticas e culturais para inscreverem social e territorialmente os sujeitos, como em estudos desenvolvidos com a Cultura Hip-Hop. A escola ainda aparece como central para encontros educativos e criações das juventudes, sendo necessário atividades mais próximas do território.

Acreditamos que a cidade participa na educação de seus habitantes, sendo as relações nela vividas constitutivas das características singulares e coletivas dos sujeitos. Oferecemos, assim, um panorama inaugural àqueles que, como nós, desejam trabalhar por cidades educativas e defender sua centralidade na promoção de encontros territoriais sensíveis e potentes, voltados ao combate das desigualdades sociais e convocando à união de afetos, sentidos e saberes.

\section{REFERÊNCIAS}

ABRANTES, P.; TEIXEIRA, A. R. A intervenção socioeducativa em territórios marginalizados: agentes de desenvolvimento local ou da ordem escolar? Revista Lusófona de Educação, v. 27, n. 27 , nov. 2014. ISSN 1646-401X. Disponível em:

https://revistas.ulusofona.pt/index.php/rleducacao/article/view/4828. Acesso em: 17 ago. 2019.

AFONSO, L. M. Juventude, música e cinema em Manaus na década de 1960: da diversão à aprendizagem musical. Revista Música Hodie, Goiânia, v. 16, n. 1, p.185-192, 2016. Disponível em: https://www.revistas.ufg.br/musica/article/view/43159/21639. Acesso em: 17 ago. 2019.

ALENCAR, J. J.; SILVA, J. S. Recursos didáticos não convencionais e seu papel na organização do ensino de geografia escolar. Geosaberes, Fortaleza, v. 9, n. 18, abr. 2018. Disponível em: http://dx.doi.org/10.26895/geosaberes.v9i18.645. Acesso em: 17 ago. 2019. 
ALENCAR, W. M. M. M.; MARTINS, C. M. S. S.; SILVA, A. K. Juventude e Gestão Social: um relato das práticas desenvolvidas pelo Projeto Gestão Social nas escolas na cidade de Juazeiro do Norte (CE). Revista de Ciências da Administração, Florianópolis, v. 17, p.197-210, dez. 2015. Disponível em: http://dx.doi.org/10.5007/2175-8077.2015v17nespp197. Acesso em: 17 ago. 2019.

ALMEIDA, S. F.; RIBEIRO JUNIOR, D.; SOUZA, R. P. A rua como espaço e tempo de possibilidades educativas. Revista Inter-Ação, Goiânia, v. 41, n. 2, p.323-336, ago. 2016. Disponível em: http://dx.doi.org/10.5216/ia.v41i2.40776. Acesso em: 17 ago. 2019.

ALVES, C. C.; HALLAL, D. R. Interações do Grafite e do Turismo em Pelotas/RS. Pixo - Revista de Arquitetura, Cidade e Contemporaneidade, v. 1, n. 1, p.114-127, set. 2017. Disponível em: http://dx.doi.org/10.15210/pixo.v1i1.10590. Acesso em: 19 ago. 2019.

ALVES, H. C.; OLIVEIRA, N. P.; CHAVES, A. D. A gente quer mostrar nossa cara, mano: hip hop na construção de identidade, conscientização e participação social de jovens em situação de vulnerabilidade social. Cadernos de Terapia Ocupacional da Ufscar, São Carlos, v. 24, n. 1, p.39-52, 2016. Disponível em: http://dx.doi.org/10.4322/0104-4931.ctoao0637. Acesso em: 17 ago. 2019.

ANDRADE, E. A.; BÓGUS, C. M. Políticas públicas dirigidas à juventude e promoção da saúde: como a proposta de auxiliares da juventude foi traduzida em prática. Interface (Botucatu), Botucatu, v. 14, n. 35, p.853-866, dez. 2010. Disponível em: http://dx.doi.org/10.1590/s141432832010005000033. Acesso em: 17 ago. 2019.

ARAÚJO, P. C. A.; NEVES, G. F. No tear da memória, travessias de história da luta do campo no cordel: educar a juventude em direitos humanos. HOLOS, v. 3, p.176-184, set. 2017. Disponível em: http://dx.doi.org/10.15628/holos.2017.5769. Acesso em: 17 ago. 2019.

ARPINI, D. M.; QUINTANA, A. M.; GONÇALVES, C. S. A rua e suas diferentes representações na percepção de jovens em situação de rua. ETD - Educação Temática Digital, Campinas, v. 12, p.4263, set. 2010. Disponível em: http://dx.doi.org/10.20396/etd.v12i0.859. Acesso em: 17 ago. 2019.

ASSIS, N.; ZANELLA, A. V. Cidade polifônica: indícios de memórias outras na paisagem. 2016. 240 f. Tese (Doutorado) - Curso de Psicologia, Centro de Filosofia e Ciências Humanas, Universidade Federal de Santa Catarina, Florianópolis, 2016. Disponível em:

https://repositorio.ufsc.br/handle/123456789/168166. Acesso em: 19 ago. 2019.

ASSIS, N.; ZANELLA, A. V.; ROSA, L. The Extended School Day and Artistic Activities: Analysis of Scientific Production Between 2000 and 2012 in Brazil. Paidéia, Ribeirão Preto, v. 24, n. 58, p. 253260, maio 2014. Disponível em: http://dx.doi.org/10.1590/1982-43272458201413. Acesso em: 17 ago. 2019.

BARBOSA, I.; FERREIRA, F. I. Monstros, máquinas e pipocas: teatro do oprimido e protesto de rua. Comunicação e Sociedade, v. 31, p.81-105, jun. 2017. Disponível em : http://dx.doi.org/10.17231/comsoc.31(2017).2606. Acesso em: 17 ago. 2019.

BARNART, F.; BAUER, L. 'Sabia que estaria aqui': relatos sobre os processos criativos do projeto 'Uma Cidade pelas Margens'. Revista Latino-americana de Geografia e Gênero, Ponta Grossa, v. 8, n. 1, p.438-467, 2017. Disponível em: http://dx.doi.org/10.5212/rlagg.v.8.i1.0025. Acesso em: 20 ago. 2019.

BATISTA, E. C.; MAZON, M. S. Trajetórias escolares de jovens assentados: estudo em Arinos/MG. Política \& Sociedade, Florianópolis, v. 14, n. 31, p.200-226, 2015. Disponível em: 
http://dx.doi.org/10.5007/2175-7984.2015v14n31p200. Acesso em: 17 ago. 2019.

BENTO, I. C.; THOMAZI, Á. R. G. Educação ambiental emancipatória na escola: possibilidades da prática educativa docente. HOLOS, v. 6, p.103-119, dez. 2013. Disponível em: http://dx.doi.org/10.15628/holos.2013.1752. Acesso em: 17 ago. 2019.

BRASIL. Fundação Coordenação de Aperfeiçoamento de Pessoal de Nível Superior. Ministério da Educação. Resultado da Avaliação Quadrienal 2017. 2017. Disponível em: http:/ /avaliacaoquadrienal.capes.gov.br/resultado-da-avaliacao-quadrienal-2017-2. Acesso em: 17 ago. 2019.

BRASIL. Fundação Coordenação de Aperfeiçoamento de Pessoal de Nível Superior. Ministério da Educação. Tabela de Áreas do Conhecimento/Avaliação. 2017. Disponível em: https://www.capes.gov.br/avaliacao/instrumentos-de-apoio/tabela-de-areas-do-conhecimentoavaliacao. Acesso em: 18 ago. 2019.

CALAÇA, G. E.; NASCIMENTO, L. A.; DINIZ, A. M. Na trilha do metal: a construção de territorialidades das bandas de heavy metal em Belo Horizonte nos anos 1980. Caderno de Geografia, Belo Horizonte, v. 28, n. 54, p.650-673, jul. 2018. Disponível em: http://dx.doi.org/10.5752/p.23182962.2018v28n54p650-673. Acesso em: 20 ago. 2019.

CASTRO, A. A.; RIBEIRO, M. T. F. Música e desenvolvimento em Salvador (Bahia), à luz da geografia crítica e ecologia dos saberes. Per Musi, Belo Horizonte, n. 31, p.235-257, jun. 2015. Disponível em: http://dx.doi.org/10.1590/permusi2015a3113. Acesso em: 17 ago. 2019.

CASTRO, L. R. Crianças, jovens e cidades: vicissitudes da convivência, destinos da cidadania. In: CASTRO, L. R. (org.). Subjetividade e cidadania: um estudo com crianças e jovens em três cidades brasileiras. Rio de Janeiro: 7letras, 2001. p. 113-156.

CECCHETTO, F.; CORRÊA, J.; FARIAS, P. Quando o projeto era moda: projetos sociais, juventudes e a política de "pacificação" no Rio de Janeiro. Brasiliana: Journal for Brazilian Studies, v. 4, n. 2, p.483-512, 2016. Disponível em: https://tidsskrift.dk/bras/article/view/21970. Acesso em: 17 ago. 2019.

CHAIGAR, V. A. M.; BORBA, R. C. S. Geografias, infâncias e pedagogia: percursos formativos na interação com a cidade do Rio Grande. Revista Brasileira de Educação em Geografia, Campinas, v. 6, n. 11, p.25-44, jan./jun. 2016. Disponível em:

http://www.revistaedugeo.com.br/ojs/index.php/revistaedugeo/article/view/371. Acesso em: 17 ago. 2019.

COELHO, G. "Sentir para entender": juventude, presença e sentidos. POLÊM!CA, v. 16, n. 4, p.1-12, nov. 2016. Disponível em: http://dx.doi.org/10.12957/polemica.2016.26456. Acesso em: 17 ago. 2019.

COIMBRA, C. M. B.; NASCIMENTO, M. L. Jovens pobres: o mito da periculosidade. In: FRAGA, P. C. P.; IULIANELLI, J. A. S. (org.). Jovens em tempo real. Rio de Janeiro: DP\&A, 2003. p. 19-37.

CORREIA-LIMA, B. C.; RIGO, A. S.; SANTOS, M. E. P. Memória organizacional e construção de identidade: uma análise da mobilização e organização social no Conjunto Palmeira. Administração Pública e Gestão Social, v. 8, n. 4, p.235-245, nov. 2016.

Disponível em: http://dx.doi.org/10.21118/apgs.v1i4.1079. Acesso em: 20 ago. 2019. 
COSTA, I. E. A contribuição do pensamento freiriano no processo de empoderamento da juventude quilombola de Paratibe, João Pessoa - PB: uma análise da experiência do projeto social Paratibe em Ação. Revista Inter-Ação, Goiânia, v. 42, n. 2, p.500-518, dez. 2017. Disponível em: http://dx.doi.org/10.5216/ia.v42i2.44016. Acesso em: 17 ago. 2019.

COSTA, R. H. Notas sobre a Educação formal, não-formal e informal. In: SIMPOM - III Simpósio Brasileiro de Pós-Graduandos em Música, 2014, Rio de Janeiro. Anais do SIMPOM. Rio de Janeiro: Unirio, 2014. v. 3, p. 436-444. Disponível em: http://www.seer.unirio.br/index.php/simpom/article/view/4578/4100. Acesso em: 17 ago. 2019.

DAMASCENA, A. A. A congada como espaço de socialização e aprendizagem: entre o passado e o presente. Revista Inter-ação, Goiânia, v. 41, n. 2, p.355-372, ago. 2016. Disponível em: http://dx.doi.org/10.5216/ia.v41i2.40803. Acesso em: 17 ago. 2019.

DIAS, A. Fazer-se escola fazendo a cidade: as festas dos escolares em Nova Iguaçu (1916-1947). Educação: Teoria e Prática, Rio Claro, v. 24, n. 47, p.77-96, dez. 2014. Disponível em: http://dx.doi.org/10.18675/1981-8106.vol24.n47.p77-96. Acesso em: 17 ago. 2019.

DIBA, D.; D'OLIVEIRA, A. F. Community Theater as social support for youth: agents in the promotion of health. Ciência \& Saúde Coletiva, Rio de Janeiro, v. 20, n. 5, p.1353-1362, maio 2015. Disponível em: http://dx.doi.org/10.1590/1413-81232015205.01542014. Acesso em: 17 ago. 2019.

FAUSTINO, G. O.; HÜNING, S. M. O Plano Juventude Viva e a rede de políticas de juventude para enfrentamento à violência em Alagoas. Estudos e Pesquisas em Psicologia, Rio de Janeiro, v. 15, n. 4, p.1413-1432, 2015. Disponível em:

http://pepsic.bvsalud.org/scielo.php?script=sci_arttext\&pid=S1808-42812015000400017. Acesso em: 17 ago. 2019.

FERREIRA, N. S. A. As pesquisas denominadas "estado da arte". Educação \& Sociedade, Campinas, v. 23, n. 79, p.257-272, ago. 2002. Disponível em: http://dx.doi.org/10.1590/s010173302002000300013. Acesso em: 19 ago. 2019.

FERREIRA, S. C. T. E se a cidade fosse nossa: a educação popular contribui na emancipação e na humanização das juventudes na cidade?. RELACult - Revista Latino-Americana de Estudos em Cultura e Sociedade, v. 4, fev. 2018. Disponível em: http://dx.doi.org/10.23899/relacult.v4i0.748. Acesso em: 17 ago. 2019.

FRANZOI, N. L.; FRANÇA, D. M. C.; OLIVEIRA, M. C. R. Escola e desenvolvimento local: encontros e desencontros. Perspectiva, Florianópolis, v. 34, n. 3, p.880-902, fev. 2017. Disponível em: http://dx.doi.org/10.5007/2175-795x.2016v34n3p880. Acesso em: 17 ago. 2019.

GADEA, C. A. et al. Trajetórias de jovens em situação de vulnerabilidade social: sobre a realidade juvenil, violência intersubjetiva e políticas para jovens em Porto Alegre - RS. Sociologias, Porto Alegre, v. 19, n. 45, p.258-299, ago. 2017. Disponível em: http://dx.doi.org/10.1590/15174522019004512. Acesso em: 19 ago. 2019.

GEHL, J. Cidades para pessoas. 3. ed. São Paulo: Perspectiva, 2015, 280 p.

GENTILE, C.; BURGOS, A. Coopercuc: percursos de valorização dos recursos locais e de convivência com o Semiárido. Sustentabilidade em Debate, Brasília, v. 7, p.136-151, dez. 2016. Disponível em: http://dx.doi.org/10.18472/sustdeb.v7n0.2016.18321. Acesso em: 19 ago. 2019. 
GIL, A. C. Métodos e técnicas de pesquisa social. 6. ed. São Paulo: Atlas, 2008. 216 p.

GONÇALVES, A. S. Reflexões sobre educação integral e escola de tempo integral. In: Centro de Estudos e Pesquisas em Educação, Cultura e Ação Comunitária (CENPEC). Educação Integral. Cadernos Cenpec, n. 2, 2º semestre. São Paulo: CENPEC/Fundação Itaú Social, 2006.

GONÇALVES, M. V. Eu nem sabia que podia entrar aqui: promoção de cidadania cultural como experiência de ressignificação de identidade de jovens em conflito com a lei. Cadernos de Terapia Ocupacional da Ufscar, São Carlos, v. 24, n. 1, p.127-137, 2016. Disponível em: http://dx.doi.org/10.4322/0104-4931.ctore0664. Acesso em: 17 ago. 2019.

GROPPO, L. A.; GOUSSAIN, E. M. F. C. S. Dimensões educativas não formais e informais das práticas culturais juvenis na cidade. Revista Inter-Ação, Goiânia, v. 41, n. 2, p.265-285, ago. 2016. Disponível em: http://dx.doi.org/10.5216/ia.v41i2.40704. Acesso em: 17 ago. 2019.

GUIMARÃES, R. G.; CARVALHO, C. O Movimento Manguebeat na mudança da realidade sociopolítica de Pernambuco. Políticas Culturais em Revista, Salvador, v. 9, n. 1, p.110-133, jan. 2016. Disponível em: http://dx.doi.org/10.9771/pcr.v9i1.16800. Acesso em: 17 ago. 2019.

HINCAPIÉ, A. El hip hop: una práctica corporal que territorializa la ciudad de Medellín. Poiésis: Revista do Programa de Pós-Graduação em Educação, Tubarão, v. 8, n. 14, p.385-402, dez. 2014. Disponível em: http://dx.doi.org/10.19177/prppge.v8e142014385-402. Acesso em: 17 ago. 2019.

KATAOKA, C. S.; ORNAT, M. J. Mapas de significados espaciais e vivência geracional de homens e mulheres nikkeys de Maringá e Londrina, Paraná. Revista Latino-americana de Geografia e Gênero, Ponta Grossa, v. 6, n. 1, p.64-90, 2015. Disponível em: http://dx.doi.org/10.5212/rlagg.v.6.i1.0005. Acesso em: 20 ago. 2019.

LARANJEIRA, D. H. P.; IRIART, M. F.; LUEDY, E. Arte como política de resistência: dispositivos cartográficos na apreensão de práticas culturais juvenis em uma cidade do Nordeste do Brasil. Etnográfica, v. 22, n. 2, p.427-452, jun. 2018. Disponível em: http://dx.doi.org/10.4000/etnografica.5614. Acesso em: 17 ago. 2019.

LÁZARO, G.; SILVA, O. Hip-hop em Angola: o rap de intervenção social. Cadernos de Estudos Africanos, n. 31, p.41-67, jun. 2016. Disponível em: http://dx.doi.org/10.4000/cea.2013. Acesso em: 17 ago. 2019.

LEBOURG, E. H.; COUTRIM, R. M. E. Eu não queria estar aqui: juventude, ensino médio e deslocamento. Educação \& Realidade, Porto Alegre, v. 43, n. 2, p.609-627, jun. 2018. Disponível em: http://dx.doi.org/10.1590/2175-623664657. Acesso em: 17 ago. 2019.

LEITE, L. H. A.; CARVALHO, P. F. L. Educação (de tempo) integral e a constituição de territórios educativos. Educação \& Realidade, Porto Alegre, v. 41, n. 4, p.1205-1226, dez. 2016. Disponível em: http://dx.doi.org/10.1590/2175-623660598. Acesso em: 17 ago. 2019.

LEITE, M. E.; MELO, M. A. S. S. Juventudes e espaço urbano: uma análise geográfica na cidade d Montes Claros-MG. Caderno de Geografia, Belo Horizonte, v. 27, n. 48, p.123-141, jan. 2017. Disponível em: http://dx.doi.org/10.5752/p.2318-2962.2017v27n48p123. Acesso em: 17 ago. 2019.

LIBERATO, A. F. H. V. Unindo e articulando questões sociais e cultura local nas aulas de Arte do Ensino Médio. Revista Matéria-Prima, v. 2, n. 3, p.135-145, 2014. Disponível em: 
https://repositorio.ul.pt/bitstream/10451/34923/2/ULFBA_mp3_135-145.pdf. Acesso em: 17 ago. 2019.

LIMA, A. Funkeiros, timbaleiros e pagodeiros: notas sobre juventude e música negra na cidade de Salvador. Cadernos Cedes, Campinas, v. 22, n. 57, p.77-96, ago. 2002. Disponível em: http://dx.doi.org/10.1590/s0101-32622002000200006. Acesso em: 17 ago. 2019.

LOPES, L. O currículo funcional para nova pedagogia urbana. Journal Of Research In Special Educational Needs, n. 1, v. 16, p.748-751, ago. 2016. Disponível em: http://dx.doi.org/10.1111/1471-3802.12331. Acesso em: 17 ago. 2019.

LOPES, R. E. et al. Recursos e tecnologias em Terapia Ocupacional Social: ações com jovens pobres na cidade. Cadernos de Terapia Ocupacional da Ufscar, São Carlos, v. 22, n. 3, p.591-602, 2014. Disponível em: http://dx.doi.org/10.4322/cto.2014.081. Acesso em: 17 ago. 2019.

MACHADO, R.; SANTOS, H. Juventude extrativista como sujeito de participação e fortalecimento comunitário. Revista de Educação Popular, Uberlândia, v. 16, n. 1, p.10-21, jun. 2017. Disponível em: http://dx.doi.org/10.14393/rep-v16n12017-art01. Acesso em: 17 ago. 2019.

MARTINS, F. Entre projeto e convivialidade: um exercício de reflexividade etnográfica em torno da socialidade juvenil em Cabo Verde. Etnográfica, v. 20, n. 1, p.77-100, fev. 2016. Disponível em: http://dx.doi.org/10.4000/etnografica.4184. Acesso em: 17 ago. 2019.

MELLO, R. C.; LASTORIA, A. C.; SANTOS, J. F. A. "Caminhar", "(re)configurar" e produzir curtasmetragens: o relato de uma prática escolar em Ribeirão Preto/SP. Espaço Plural, v. 16, n. 32, p.120148, 2015. Disponível em: http://hdl.handle.net/11449/168033. Acesso em: 17 ago. 2019.

MELO, D. B.; AMARAL, I. T.; CARVALHO, R. C. M. A experiência do Espaço Nordeste Pedro II: reconhecimento, usufruto e valorização do patrimônio cultural. Revista FSA, Teresina, v. 14, n. 1, p.245-264, jan. 2017. Disponível em: http://dx.doi.org/10.12819/2017.14.1.12. Acesso em: 19 ago. 2019.

MENDES, M. F.; PÉREZ, C. L. V. Uma "Rocinha" de livros: percursos poéticos dos processos de formação de uma professora alfabetizadora e seus alunos leitores. Práxis Educativa, Ponta Grossa, v. 11, n. 2, p.410-433, maio./ago. 2016. Disponível em: http://dx.doi.org/10.5212/praxeduc.v.11i2.0006. Acesso em: 17 ago. 2019.

MENEZES, I. G. Enxada versus caneta: Educação como prerrogativa do urbano no imaginário de jovens rurais. Revista Eletrônica de Educação, São Carlos, v. 3, n. 1, p.24-38, maio 2009. Disponível em: http://www.reveduc.ufscar.br/index.php/reveduc/article/view/28. Acesso em: 17 ago. 2019.

MENEZES, J. A.; COSTA, M. R.; FERREIRA, D. F. T. Escola e movimento Hip-hop: o campo das possibilidades educativas para a juventude. ETD - Educação Temática Digital, Campinas, v. 12, p.83-106, set. 2010. Disponível em: http://dx.doi.org/10.20396/etd.v12i0.861. Acesso em: 17 ago. 2019.

MISSAU, L. D.; RONSINI, V. M. A representação de identidades juvenis no audiovisual comunitário. Cuadernos de Información, n. 31, p.117-128, dez. 2012. Disponível em: http://dx.doi.org/10.7764/cdi.31.433. Acesso em: 20 ago. 2019.

MONZELI, G. A.; FERREIRA, V. S.; LOPES, R. E. Entre proteção, exposição e admissões condicionadas: travestilidades e espaços de sociabilidade. Cadernos de Terapia Ocupacional da 
Ufscar, São Carlos, v. 23, n. 3, p.451-462, 2015. Disponível em: http://dx.doi.org/10.4322/01044931.ctoao0518. Acesso em: 17 ago. 2019.

MORE: Mecanismo online para referências, versão 2.0. Florianópolis: UFSC Rexlab, 2013. Disponível em: http://www.more.ufsc.br/. Acesso em: 18 ago. 2019.

MORENO, R. C.; ALMEIDA, A. M. F. O engajamento político dos jovens no movimento Hip-hop. Revista Brasileira de Educação, Rio de Janeiro, v. 14, n. 40, p.130-142, abr. 2009. Disponível em: http://dx.doi.org/10.1590/s1413-24782009000100011. Acesso em: 17 ago. 2019.

MOURA, L. B. A.; OLIVEIRA, C.; VASCONCELOS, A. M. N. Violências e juventude em um território da Área Metropolitana de Brasília, Brasil: uma abordagem socioespacial. Ciência \& Saúde Coletiva, Rio de Janeiro, v. 20, n. 11, p.3395-3405, nov. 2015. Disponível em:

http://dx.doi.org/10.1590/1413-812320152011.17442014. Acesso em: 19 ago. 2019.

MOURA, L. A.; GUERRA, P. Contributos para a emergência de uma juventude sónica: a constituição da cena noise das Caldas da Rainha. Cidades, Comunidades e Territórios, n. 32, p.158-179, jun. 2016. Disponível em: http://dx.doi.org/10.15847/citiescommunitiesterritories.jun2016.032.art10. Acesso em: 19 ago. 2019.

NASCIMENTO, A. Das bancas de matraquilhos ao "campo dos caranguejos", dos estádios aos terreiros: campos de jogos num espaço microinsular do tempo colonial ao pós-independência.

Cadernos de Estudos Africanos, n. 26, p.177-222, dez. 2013. Disponível em: http://dx.doi.org/10.4000/cea.1166. Acesso em: 19 ago. 2019.

NOGUEIRA, M. L. M. Subjetividade e materialidade: cidade, espaço e trabalho. Fractal: Revista de Psicologia, Rio de Janeiro, v. 21, n. 1, p.69-85, abr. 2009. Disponível em: http://dx.doi.org/10.1590/s1984-02922009000100006. Acesso em: 19 ago. 2019.

NUNES, N. A. et al. Participação comunitária como prática de inovação social: um estudo de caso no Centro Educacional Marista Lúcia Mayvorne. Revista Eletrônica de Estratégia \& Negócios, Florianópolis, v. 10, n. 2, p.154-180, dez. 2017. Disponível em:

http://dx.doi.org/10.19177/reen.v10e22017154-180. Acesso em: 17 ago. 2019.

OLIVEIRA, V. H. N.; LACERDA, M. P. C. Culturas juvenis e pertencimento urbano: mapeando os fluxos juvenis na cidade. Revista FSA, Teresina, v. 15, n. 2, p.110-124, mar. 2018. Disponível em: http://dx.doi.org/10.12819/2018.15.2.6. Acesso em: 17 ago. 2019.

ORZECHOWSKI, S. T. A pedagogia e a educação nos espaços escolares e não escolares na Unicentro/Paraná: uma construção curricular a partir das políticas educacionais. Revista Espaço do Currículo, João Pessoa, v. 10, n. 2, p.290-309, ago. 2017. Disponível em: http://dx.doi.org/10.15687/rec.v10i2.35144. Acesso em: 17 ago. 2019.

PASQUIM, H. M.; CAMPOS, C. M. S.; SOARES, C. B. Projetos voltados aos jovens em instituições sociais: atividades fragmentadas e desresponsabilização do poder público. Saúde e Sociedade, São Paulo, v. 25, n. 1, p.198-205, mar. 2016. Disponível em: http://dx.doi.org/10.1590/s010412902015139991. Acesso em: 17 ago. 2019.

PENHA, J. M.; MELO, J. A. B. Geografia, novas tecnologias e ensino: (re)conhecendo o "lugar" de vivência por meio do uso do Google Earth e Google Maps. Geo UERJ, Rio de Janeiro, n. 28, p.116151, maio 2016. Disponível em: http://dx.doi.org/10.12957/geouerj.2016.13119. Acesso em: 17 ago. 2019 . 
PEREIRA, A. B. Outros Ritmos em Escolas da Periferia de São Paulo. Educação \& Realidade, Porto Alegre, v. 41, n. 1, p.217-237, mar. 2016. Disponível em: http://dx.doi.org/10.1590/2175623654713. Acesso em: 19 ago. 2019.

RAMÍREZ, I. M. A. Os imaginários urbanos das pessoas jovens residentes em Heredia, Costa Rica: uma aproximação desde as práticas sócio-espaciais. Geo UERJ, Rio de Janeiro, n. 29, p.511-542, dez. 2016. Disponível em: http://dx.doi.org/10.12957/geouerj.2016.22300. Acesso em: 17 ago. 2019.

RAPOSO, O. Coreografias de evasão: segregação e sociabilidade entre os jovens do break dance das favelas da Maré. Etnográfica, v. 16, n. 2, p.315-338, jun. 2012. Disponível em: http://dx.doi.org/10.4000/etnografica.1518. Acesso em: 17 ago. 2019.

RIBEIRO, E.; MACEDO, S. Notas sobre políticas públicas de juventude no Brasil: conquistas e desafios. Revista de Ciencias Sociales, Montevideo, v. 31, n. 42, p.107-126, jun. 2018. Disponível em: http://www.scielo.edu.uy/scielo.php?script=sci_arttext\&pid=S0797-55382018000100107. Acesso em: 18 ago. 2019.

SALES, C. M. V. Juventude, espaços de formação e modos de vida. ETD - Educação Temática Digital, Campinas, v. 12, p.24-41, set. 2010. Disponível em: http://dx.doi.org/10.20396/etd.v12i0.858. Acesso em: 19 ago. 2019.

SANTIBAÑEZ, I. H. Youth Activism in Chile: from urban educational inequalities to experiences of living together and solidarity. Educação \& Realidade, Porto Alegre, v. 43, n. 3, p.837-863, set. 2018. Disponível em: http://dx.doi.org/10.1590/2175-623678811. Acesso em: 17 ago. 2019.

SANTOS, E. O papel desempenhado pela idade na configuração das práticas sociais de lazer de jovens da cidade de Canoas/RS. Revista Mackenzie de Educação Física e Esporte, v. 7, n. 2, p.13-25, 2008. Disponível em: http://editorarevistas.mackenzie.br/index.php/remef/article/view/579. Acesso em: 19 ago. 2019.

SANTOS, F. R.; BEZERRA NETO, L. Práxis educativa para as populações campesinas brasileiras: do ruralismo pedagógico ao materialismo histórico-dialético. Acta Scientiarum, Maringá, v. 39, n. 4, p.453-467, set. 2017. Disponível em: http://dx.doi.org/10.4025/actascieduc.v39i4.31676. Acesso em: 19 ago. 2019.

SANTOS, M.; LEITE, T. P. “O rap é uma coisa que conecta, tá ligado?!”: ressignificando contextos de jovens em cumprimento de medida socioeducativa. Revista Labor, Fortaleza, v. 1, n. 17, p.42-61, jul. 2017. Disponível em: http://dx.doi.org/10.29148/labor.v1i17.19298. Acesso em: 17 ago. 2019.

SANTOS, M. A Natureza do Espaço: Técnica e Tempo. Razão e Emoção. 4. ed. São Paulo: EDUSP - Editora da Universidade de São Paulo, 2006.392 p. (Milton Santos).

SCHWEDE, G.; ZANELLA, A. V. Olhares de crianças a relevar a polifonia da cidade. Psico-USF, Itatiba, v. 18, n. 3, p.395-406, dez. 2013. Disponível em: http://dx.doi.org/10.1590/s141382712013000300006. Acesso em: 17 ago. 2019.

SIEBER, S. S.; GOMES, R. A. O plano municipal de convivência com o Semiárido como instrumento discursivo: um estudo de caso no sertão de Pernambuco, Brasil. Sustentabilidade em Debate, Brasília, v. 7, p.226-238, dez. 2016. Disponível em: http://periodicos.unb.br/index.php/sust/article/view/16179. Acesso em: 19 ago. 2019. 
SILVA, C. A.; RAINHA, F. A. Metodologia de ensino de educação ambiental em escola situada na área costeira da Baía de Guanabara. Revista de Gestão Costeira Integrada, Lisboa, v. 13, n. 2, p.181-192, jun. 2013. Disponível em: http://dx.doi.org/10.5894/rgci399. Acesso em: 17 ago. 2019.

SILVA, J. C.; GIOVINAZZO JUNIOR, C. A. Socioeducação e juventude: as ações das ONGs na cidade de São Paulo. Impulso, Piracicaba, v. 26, n. 66, p.67-85, ago. 2016. Disponível em: https://www.metodista.br/revistas/revistasunimep/index.php/impulso/article/download/2845/1810. Acesso em: 17 ago. 2019.

SILVA, M. C. A. A camisa do colégio: a reprodução de estigmas sociais pela escola e a construção de identidades para as juventudes cariocas (2008). Ponto Urbe, n. 5, out. 2014. Disponível em: http://dx.doi.org/10.4000/pontourbe.1479. Acesso em: 17 ago. 2019.

SILVA, R. C. M. Do Ipê Roxo na Cidade Nova: experiência etnográfica e aprendizagem situada. Etnográfica, v. 20, n. 1, p.119-142, fev. 2016. Disponível em: http://dx.doi.org/10.4000/etnografica.4225. Acesso em: 17 ago. 2019.

SILVA, V. C.; COUTO, E. S. Interfaceamentos contemporâneos: tecnologias digitais e tribos urbanas no contexto escolar. Educação em Revista, Belo Horizonte, v. 28, n. 2, p.333-346, jun. 2012. Disponível em: http://dx.doi.org/10.1590/s0102-46982012000200015. Acesso em: 19 ago. 2019.

SIMÕES, M. et al. Profanando-e-resistindo: sobre muros e pertencimentos. Pixo - Revista de Arquitetura, Cidade e Contemporaneidade, v. 1, n. 1, p.24-37, set. 2017. Disponível em: http://dx.doi.org/10.15210/pixo.v1i1.11140. Acesso em: 17 ago. 2019.

SOARES, C. L. Uma educação pela natureza: o método de educação física de Georges Hébert. Revista Brasileira de Ciências do Esporte, v. 37, n. 2, p.151-157, abr. 2015. Disponível em: http://dx.doi.org/10.1016/j.rbce.2014.11.016. Acesso em: 17 ago. 2019.

SOUZA, E. C.; SOUZA, H. R.; ORRICO, N. R. Metamorfoses do eu: estudantes rurais nas escolas urbanas. ETD - Educação Temática Digital, Campinas, v. 17, n. 3, p.542-557, nov. 2015. Disponível em: http://dx.doi.org/10.20396/etd.v17i3.8638272. Acesso em: 17 ago. 2019.

SOUZA, T. D.; BERNARDES, A. Da rua à internet, há a rua: sociabilidade e identidade Hip-hop na cidade de Macaé, Rio De Janeiro. Raega: O Espaço Geográfico em Análise, v. 42, p.21-35, dez. 2017. Disponível em: http://dx.doi.org/10.5380/raega.v42i0.43970. Acesso em: 17 ago. 2019.

TAKEITI, B. A.; VICENTIN, M. C. G. A produção de conhecimento sobre juventude(s), vulnerabilidades e violências: uma análise da pós-graduação brasileira nas áreas de Psicologia e Saúde (1998-2008). Saúde e Sociedade, São Paulo, v. 24, n. 3, p.945-963, set. 2015. Disponível em: http://dx.doi.org/10.1590/s0104-12902015131060. Acesso em: 17 ago. 2019.

TAKEITI, B. A.; VICENTIN, M. C. G. Jovens (en)cena: arte, cultura e território. Cadernos de Terapia Ocupacional da Ufscar, São Carlos, v. 24, n. 1, p.25-37, 2016. Disponível em: http://dx.doi.org/10.4322/0104-4931.ctoao0667. Acesso em: 17 ago. 2019.

TOMMASI, L. Juventude, projetos sociais, empreendedorismo e criatividade: dispositivos, artefatos e agentes para o governo da população jovem. Passagens: Revista Internacional de História Política e Cultura Jurídica, Rio de Janeiro, v. 6, n. 2, p.287-311, ago. 2014a. 
TOMMASI, L. Tubarões e peixinhos: histórias de jovens protagonistas. Educação e Pesquisa, São Paulo, v. 40, n. 2, p.533-548, jun. 2014b. Disponível em: http://dx.doi.org/10.1590/s151797022013005000025. Acesso em: 17 ago. 2019.

TORRALBA, R. Cartografias no Morro da Conceição: abrir brechas no corpo da cidade. Revista Brasileira de Estudos da Presença, Porto Alegre, v. 8, n. 2, p.323-347, jun. 2018. Disponível em: http://dx.doi.org/10.1590/2237-266069118. Acesso em: 17 ago. 2019.

TSOLAKIS, M. Street Discussion Spaces in Post-conflict Côte d'Ivoire: non-formal learning, dialogue and daily life. Educação \& Realidade, Porto Alegre, v. 43, n. 3, p.817-836, set. 2018. Disponível em: http://dx.doi.org/10.1590/2175-623674797. Acesso em: 17 ago. 2019.

VIGANO, S. M. M.; LAFFIN, M. H. L. F. Perspectivas e desafios na gestão do ProJovem Urbano em Santa Catarina. Revista Espaço do Currículo, v. 10, n. 1, p.92-105, abr. 2017. Disponível em: http://dx.doi.org/10.15687/rec.v10i1.33368. Acesso em: 17 ago. 2019.

ZAGO, N. Migração rural-urbana, juventude e ensino superior. Revista Brasileira de Educação, Rio de Janeiro, v. 21, n. 64, p.61-78, mar. 2016. Disponível em: http://dx.doi.org/10.1590/s141324782016216404. Acesso em: 17 ago. 2019.

ZANELLA, A. V.; TITON, A. P. Análise da produção científica sobre criatividade em programas brasileiros de pós-graduação em psicologia (1994 - 2001). Psicologia em Estudo, Maringá, v. 10, n. 2, p.305-316, ago. 2005. Disponível em: http://dx.doi.org/10.1590/s1413-73722005000200018. Acesso em: 17 ago. 2019.

ZANOTTO, L.; ALVES, F. D.; SOMMERHALDER, A. Relações educativas de professoras com crianças de zona rural: uma leitura das práticas pedagógicas em um contexto de escola urbana. Revista Ibero-Americana de Estudos em Educação, Araraquara, v. 12, n. 4, p.2058-2071, dez. 2017.

Disponível em: http://dx.doi.org/10.21723/riaee.v12.n4.out./dez.2017.8915. Acesso em: 17 ago. 2019.

Submetido: $09 / 04 / 2020$

Aprovado: 03/06/2020 